\title{
Acquiring Basic Chemistry Concepts through Virtual learning in Nigerian Senior Secondary Schools
}

Michael Olubunmi Odewumi ${ }^{1}$, Ayotunde Atanda Falade ${ }^{2}$, Adewale Olusegun Adeniran $^{3}$, David Akinjide Akintola ${ }^{4}$, Grace O. Oputa ${ }^{5}$, Sunday Abiodun Ogunlowo ${ }^{6}$ ${ }_{1,2,3,4,5,6}$ Faculty of Education, University of Ilorin, Nigeria

\section{DOI: 10.23917/ijolae.v2i1.7832}

Received: March $6^{\text {th }}, 2019$. Revised: November $1^{\text {st }}, 2019$. Accepted: November $7^{\text {th }}, 2019$. Available Online: November 11 $1^{\text {th }}, 2019$. Published Regulary: January 1 ${ }^{\text {st }}, 2020$.

\begin{abstract}
Virtual learning has emerged as an ideal platform for learning. Different e-learning packages has been developed to solve instructional problems globally, but in Nigeria few instructors are aware of the usage of these technologies. Therefore, the study examined the acquisition of basic chemistry practical through virtual among the Senior Secondary School learners in Ado Ekiti, Ekiti State. Nigeria. The study further considered gender and achievement level of the students taught with virtual learning. The quasiexperimental designed method was adopted, sample constituted of 28 Senior Secondary School II Chemistry students, of which fourteen (14) were male and fourteen (14) also female. The results reveal that virtual learning enhances students' understanding of laboratory chemistry concepts, acquisition and improve performances in chemistry as an alternative to actual chemistry laboratory in Nigerian Senior Secondary Schools.
\end{abstract}

Keywords: information communication technology, virtual learning, sciences, gender

Corresponding Author:

Michael Olubunmi Odewumi, Faculty of Education, University of Ilorin, Nigeria

e-mail:agbegilerebunmi2@gmail.com

\section{Introduction}

Information Communication and Technology (ICT) referred to tactic for collecting, collating, organizing, manipulating and drawing of assumption on data. It is also an exchange of information amid of people from one location to another. Ede and Ariyo (2014) and Fabunmi (2012) explained that ICT have become increasingly relevant tools to accelerate social, economic and educational sectors. Rosandich (2014) stated that ICT serves as the engine that is rotating the wheel of today's economy, government and education. The influence of ICT on teaching and learning is enormous. Nwoke and Akukwe (2012) stressed that ICT gives learners unique opportunities to learn individually according to their own level of understanding and provides for them instant feedback on their intellectual act. Rienhoff, Hopwood, Fischer, Strauss, Baker and Schorer (2014) and Yang and Heh (2007) concluded that positive effectiveness of ICT instruction as unquantifiable.

Hettiarachchi and Wickramasinghe (2016) expressed that Information Technology approach to instructions, has brought a great shift from teacher centered which is traditional learning methodology to learner centered method of teaching especially sciences. Chemistry is known to be a branch of science that processed the fundamental ingredients to technology dealing directly with both practical and experimental 
understanding of basic natural phenomena (Arokoyu \& Ugonwa 2012). It was said that chemistry contributed greatly to value of life and nation building which cannot be over emphasised in all aspects (Olibie, Ezoem \& Ekene, 2014).

Teaching of sciences are facing quite a lot of problem, studies have itemized some of them in different direction, for example, WAEC (2013) reported that poor performance of chemistry students in both internal and external examinations yearly are not encouraging. Njoku (2007) noted that secondary and tertiary chemistry students also exhibits poor and deplorable results over the years. Copriady (2014) stated that teaching chemistry in secondary schools is often linked with many challenges of which teachers' competency is inclusive. The study of Schutt and Linegar (2013) also Omorogbe and Celestine (2013) mentioned the abstract nature of the chemistry concepts and topics in the curriculum as another strong factor. Also, poor methodology (Machina, 2012). Lack of motivation is also identified as another crucial factor of poor learners outcome in sciences (Glynn, Taasoobshirazi \& Brickman, 2009) and also (Herga, Čagran \& Dinevski, 2016). In essence, Celestine (2013) stressed that inadequate qualified hands to train the science teachers is also a factor on the poor students' performances of sciences. Lawrence (2011) and Nikolaev and Chugunov (2012) lamented of the situation of education as complicated in respect of problems resulting from the national economic and political instability of the State.

In respect to these challenges, suggestions for improvement and to address these challenges are being examined by the scholars. For example, the study of Rajasingham (2007) mentioned field work, e-learning and project works as a method of instruction that can easily facilitate to alleviate aforementioned problems. Hume and Berry, (2013) suggested that constant laboratory work and utilization of content design is way to solve learning problems in sciences. More so, Lawrence (2011) mentioned the usefulness and solving problems of teaching of sciences through virtual laboratory as it is paramount in recent time. In essence, Gambari and Yusuf (2014) explained that virtual learning is an innovative techniques of instruction that is very useful for teaching and learning of sciences especially chemistry. French (2014) concluded that learning is more of experiments in the scope of virtual environment and it is more valuable than in real laboratories. However, virtual learning may be used and at same times be preferred for alternative and supportive for chemistry instruction.

In this regards, researches have examined the meaning of virtual learning, many scholars have discussed virtual learning in different perspective. For instance, Unanma, Abugu, Dike and Umeobika (2013) explained that virtual learning is a reality and arena that offers repeatable, safe and conducive environment for skills that are not possible to undergoes in real-world. The study of Jeschke, Richter and Zorn (2010) clarified virtual laboratories as a stimulants, provider also offers the students with significant practical experiences. Also, Abeldina, Moldumarova, Abeldina and Moldumarova (2015) submitted that a virtual learning environment consists of a designed software and a system of instruction for educational establishment and organisation monitored under the auspices of an experts which creates communication border for the teachers and as well for students in facilitating learning process. Jasieński (2014) concluded that a virtual classroom can duplicate a normal classroom of brick and mortar for instructional purposes. Moreover, 
virtual learning environment is learning that is acquired through interaction with digitally devices for delivery of learning content. It is also the learning that carried out via integration of electronic dialogue for example activities on web platforms (Bouchard, 2011) and (Tirp, Steingröver, Wattie, Baker \& Schorer, 2015). For this reason, Hettiarachchi and Wickramasinghe (2016) explicated that virtual learning environment is an online learning podium that allows instructors to share instructional content with both male and female students through the web, example of these are WebCT, Moodle and Blackboard.

On gender and sciences, it has been identified by many studies that gender as a factor influences greatly the performances of the science students especially in the senior secondary school level within Nigeria. Jimoh (2004) and Khairulanuar, Nazre, Sairabanu and Norasikin (2010) reported that gender differences specifically in favour of the male science scholars. In contrast, Martin and Parker (2014) expressed the concern of faculty female using virtual environment than male. Also, Ajaja and Eravwoke (2010) stated that gender did not influence on the academic performance of learners. More so, Olson (2002) confirmed that male students were performing less than their female counterparts in sciences. These aforementioned studies have contradictory establishments and had led to considering gender as a moderating factor and variable in this present study. The recent review showed the inconclusiveness of the findings on gender and performances of the science students.

Furthermore, many studies are paying attention to the gender ability level and achievement of the students. According to West African Examination Council results reported in the year 2015, male students excel in their performances than their female colleague in Chemistry subject in the past five years, this revealed that good and outstanding performance of the male learners over the female (Yang \& Heh, 2007). The study of Miyake (2010) observed that the disparity between female and male science scholars especially in achievements in higher education revealed that female are few in science oriented courses than when compared to their male counterpart.

Many studies have revealed positive impact of virtual learning to students. For example, the study of Rosandich (2014) researched on the transferring of a motor skill within and between basketball and darts. Also, Unanma, Abugu, Dike, and Umeobika (2013) worked on virtual realities in learning environment that stimulates efficiency and difference in training. More so, Abeldina, Moldumarova, Abeldina, and Moldumarova (2015) examined the virtual environment for teaching science subjects in schools. Yang, and Heh, (2007) looked at the efficacy of the virtual physics laboratory (VPL) on the scientific progression, they concluded that the learners within the experimental setting significantly achieve more than the others in the scope of traditional laboratory activities. Unanma, Abugu, Dike, and Umeobika (2013) researched into the skill in the virtual and actual learning environment on throwing, the study stressed the significant differences in condition and interaction test which took measure in enhancing the virtual group. Also, Altun, Feyzioğlu, and Demirağ (2011) studied the effectiveness of virtual chemistry teaching on the scientific process skills, the study revealed that virtual chemistry was effective in teaching of scientific process skills. In essence, virtual learning is established as a good method of instruction which promotes effective instruction through web. 
Scholars have argued that virtual learning provides the students opportunity to assist and influence each other. In other words, studies have confirmed the usefulness of virtual in learning different discipline on the school curriculum. For instance, Dede, Salzman and Loftin (1994) mentioned that the virtual learning laboratory is an alternative learning environment to laboratory that endorses full involvement of learner individual or collaboratively. Herga, Čagran and Dinevski (2016) expressed that virtual laboratory provides picky reward that present teaching and learning in meaningful way. Domingues, Rocha, Dourado, Alves and Ferreira (2010) opined that both virtual and real world experience provides laudable experiences. In essence, It is clear that one can deduced that virtual learning brings positive and effective classroom instruction to the door step of the learners.

However, there is a need for the nation to adopt Information Communication Technology (ICT) oriented method of instruction for schools and colleges. Unfortunately, awareness and utilisation of this method of instructions, that is virtual learning are yet to be fully embraced by the primary and secondary school teachers in Nigeria. It is on this note that the study examined the acquisition of basic chemistry practical through virtual laboratory among Senior Secondary School students in Ado Ekiti, Nigeria. The study further considered at gender and achievement level of the students taught with virtual learning.

The research questions have been raised in other to direct course of the study. There are (1) whethere there is difference in the performances of che-mistry learners taught with virtual environment and those taught without, (2) whethere there is any difference in the performances of male and female chemistry students taught with virtual learning, and (3) whethere there is significant difference in the mean scores of low, medium and high ability of chemistry students taught with virtual learning.

There are some hypotheses were formulated for this study, which are:

Ho1 There is no significant difference in the performance of chemistry learners taught with virtual environment and those with conventional method.

Ho2 There is no significant difference in the performances of female and male chemistry learners taught with virtual environment.

$\mathrm{Ho}_{3}$ There is no significant difference in the mean scores of high, medium and low ability of chemistry students taught with virtual learning.

\section{Method}

The study used quasi-experimental type of post-test design which involves administering a specify summative objective test items after the treatment to the selected sample. The population for this study was extracted from the entire public Senior Secondary School II Chemistry scholars in Ado Ekiti, Ekiti State, Nigeria. In essence, the study sampled twenty eight (28) students, fourteen (14) were male and fourteen (14) also female. The schools used for the study were preferred purposively on these criteria; equivalence (teachers, facilities and chemistry laboratory), gender composition (mixed schools), school type (public schools). Other were ICT equipments (computer sets under the close monitoring of the School Networking Programme) and also, exposure (teachers and student exposure to computer usage). Also, these two equivalent selected mixed schools were designated to both the control group (chemistry students taught with normal teaching and learning in the classroom with appropriate instructional materials) and 
experimental (the treatment set of learners, that is students taught with virtual learning environment) the students were sampling based on randomise technique and stratified sampling technique was also utilised to group the students to female and male and their level of their ability in terms of low, medium and high guided by the students performances in the last summative promotion examinations in chemistry (in Senior Secondary I) with this yardstick; Upper (75-100\%), Higher which is (50 $74 \%)$, Medium (49-24\%), and Low (0-25\%).

The Experimental Procedure was taken care of the objectives and process of the experiments were well stated in the operational manual that were given to both the students and the instructors. The learners were exposed to virtual instruction, through the computers for the experimental groups. Students were instructed to be conscious and mindful of the instruction. The instruments used (package and test) were adapted from Ogunlowo (2016) named as the Laboratory Software Package (LSP) and test instrument that is Practical Chemistry Test (PCT). The test instrument used in producing data for the study consisted of fifty (50) multiple choice objective items premeditated to measure specified learning outcomes related to the virtual learning environment. A stem is followed by five (5) options lettered (A-E) out of which only "one" was absolutely correct. Chemistry students were therefore instructed to select the only one option as answer for each given item. All the options were nearly answers to the item. In essence the total correct marks of the each student is placed over fifty (50).

The researcher handles the available Information and Communication Technology facilities on the ground for the teaching of the experimental group assign each computer to a student for the process of teaching.
Laboratory Software Package is a Web based instructional media distributed through online/ network to all available computers. Students logged through typing their usernames and passwords at the home page. The menu options on the left include topic option, The topic information contained a brief summary of the topics, bringing the user to the main menu, where the topics are listed on the top left hand side of home page. Having logged in through selection of a topic. A series of instruction are automatically displayed along with the topic, students follow the sequence, after satisfying with the page, the next menu is clicked continuously till the end of the topic in last page. The assignments section were of homework based for learners to practice with the topic of instructions.

While the Chemistry teachers in the two schools with the research assistants were employed to team teach the conventional group in the given topics (Mole concept, Electrolysis, chemical equilibrium, isomerism, IUPAC nomenclature) for six weeks of two periods per weeks, each period consists of 40 minutes. The first week starts with the instructions guiding the course of study. The lesson starts fully in the second week with the experimental group accomplishing the virtual learning through the Laboratory Software Package in the chemistry laboratory and the other group the conventional group taught with conventional teaching compliment with appropriate teaching materials in line with the stated objectives in the planned lesson note written prior and examined by a lecturer in the Department of Science Education, University of Ilorin. Ilorin. Nigeria. After the thorough teaching of prescribed topics for four weeks, with the two groups, the students were gathered together and the adapted objective test instrument were administered as a 
summative in the Chemistry Laboratory to students on paper based and score each student over fifty marks.

\section{Result and Discussion}

To answer the first question can be illustrated in table 1, as follows:

Table 1 The Means of Chemistry Learners Taught with Virtual Environment and Those Taught with Conventional Method.

\begin{tabular}{rrrr}
\hline Grouping & Number & Mean & Standard D. \\
\hline Experimental & 14 & 35.0000 & 5.00000 \\
Conventional & 14 & 33.0000 & 5.37742 \\
\hline
\end{tabular}

Table 1 revealed that the experimental chemistry students mean was 35.0000 and the mean of conventional chemistry students taught with conventional method was 33.0000 , in favour of experimental group.
Research Question 2: Is there any difference in the performances of male and female chemistry students taught with virtual environment?

The question is answered as follows:

Table 2. The Means of Male and Female Chemistry Learners Taught with Virtual Environment

\begin{tabular}{rrrr}
\hline Grouping & N & Mean & Std. Deviation \\
\hline Male & 14 & 35.0000 & .00000 \\
Female & 14 & 31.2000 & 5.55278 \\
\hline
\end{tabular}

Table 2 shows that the mean of male chemistry students taught with virtual learning environment with male chemistry students mean of 35.0000 and the female chemistry students with 31.2000 , in favour of male students.
$\mathbf{H}_{\mathbf{0 1}}$ : There is no significant difference in the performance of chemistry learners taught with virtual environment and those with conventional method.

To test this hypothesis, t-test statistics was used, result is reported as in Table 3.

Table 3. t-test Mean of both Experimental and Conventional Chemistry Groups.

\begin{tabular}{lcccccc}
\hline Grouping & No & Mean & Std D. & df & T-value & Sig. (2-tailed) \\
\hline School A & 14 & 35.0 & 5.000 & 26 & 612 & 546 \\
School B & 14 & 33.0 & 5.377 & & & \\
\hline
\end{tabular}

In Table 3, the post-test mean of experimental and conventional groups were compared. The calculated $F$ value of 612 is higher than 0.05 alpha levels. This implies that there is no significant difference between the post-test mean scores of the treatment and conventional group. That is, the scores did not differ significantly from the experimental and control groups.
Therefore, the null hypothesis is accepted, meaning there is no significant difference in students performance taught with either virtual or conventional methods.

$\mathbf{H}_{\mathbf{0} 2}$ : There is no significant difference in the performances of female and male chemistry learners taught with virtual environment. 
In testing the hypothesis, t-test statistics is used to compare the means of female and male experimental group. This result is as stated in Table 4.

Table 4. t-test Statistics Comparing The Means Score of The Male and Female Experimental Group

\begin{tabular}{ccccccc}
\hline Grouping & No & Mean & Stand. d. & df & T-value & Sig. (2-tailed) \\
\hline Male & 14 & 35.000 & 5.00000 & 26 & 1.166 & 254 \\
Female & 14 & 31.000 & 5.37742 & & & \\
\end{tabular}

Table 4 , indicates that the $\mathrm{t}$ value which is 1.166 is significant, in that the significant .254 value is bigger than alpha levels of 0.05 . The result clearly shows that no significant difference in mean of female and male in experimental group. Therefore, the null hypothesis is not rejected but accepted. In other words the result suggested that male and female do perform equally in the test given.
$\mathbf{H}_{\mathbf{0} 3}$ : There is no significant difference in the mean scores of upper, high, medium and low ability level of chemistry students taught with virtual environment.

To test this hypothesis, Analysis of variance (ANOVA) statistics was used to compare the scores of the low, medium, High and Upper ability level in experimental group. This result is revealed in Table 5.

Table 5. ANOVA Statistics Comparing The Scores Of The Low, Medium and High in Experimental Learners.

\begin{tabular}{lrrrrr}
\hline Source & Type III Sum of Squares & df & \multicolumn{1}{c}{ Mean Sq. } & \multicolumn{1}{c}{ F } & Sig \\
\hline Corrected Model & $1894.944^{\mathrm{a}}$ & 2 & 947.472 & 24.458 & .000 \\
Intercept & 51995.487 & 1 & 51995.487 & 1342.186 & .000 \\
FACTOR & 1894.944 & 2 & 947.472 & 24.458 & .000 \\
Error & 968.485 & 25 & 38.739 & & \\
Total & 125360.000 & 28 & & & \\
Corrected Total & 2863.429 & 27 & & & \\
\hline
\end{tabular}

a. $\mathrm{R}$ Squared $=.662$ (Adjusted R Squared $=.635$ )

Table 5, presents the comparison of mean scores of lower, Medium and high performance levels of the experimental group. The $\mathrm{F}$ value of 24.458 is not significant since the significant .000 value is lesser than 0.05 alpha levels. This consequence implies that there is existing significant difference between the mean scores of high, medium and low. That is, the scores did differ significantly from the experimental groups. The null hypothesis therefore is rejected.

The study is aimed to investigate acquired basic chemistry concepts through virtual learning in Nigerian Senior Secondary Schools. Based on the results, the report of analysis on hypothesis one (1) on the performances of chemistry students taught with virtual learning was accepted. The present findings conformed with Mutlu and Şeşen (2016) who reported that a virtual chemistry laboratory grants a positive scientific skills and researches for learners. Moreover, this finding also supported the conclusion of Altun, Feyzioğlu and Demirağ (2011) who succumbed that virtual chemistry laboratory significantly promote theoretical and practical learning. Furthermore, the finding also agreed with Yohon and Zimmerman (2006) who established that virtual laboratory instruction was more 
effective for increasing students' cognitive learning.

Moreover, the findings agreed with Lopukhova and Makeeva, (2017) who stated that virtual learning gives opportunities and promotes effective learning environment that fosters and increase students' intellect. Also the study further supported Rosandich (2014) who submitted that virtual learning significantly useful for acquiring basic techniques of skills in basketball and darts. This corroborate with finding of French (2014) who reported the acquisition of functional of online classroom instruction and home instructional strategies through virtual learning. In essence, the study conform with Dalgarno, Bishop and Bedgood (2003) who suggested that learners do gain more experiences and skills via virtual environment.

In the same vein the study of Jasieński (2014) who suggested that learners should be encouraged and the sense of anonymity through virtual learning. The finding agrees with Meisner, Hoffman and Turner (2008) who established that virtual environment is a driven exemplary method and viable alternative for students learning practical physics. However, the finding negates the finding of Yohon and Zimmerman (2006) who reported the significant difference in favour of the experimental group. Similarly, the finding did not support the finding of Herga, Čagran and Dinevski (2016) who confirmed the significant difference in experimental and conventional groups. In essence, it is true that virtual learning improves cognitive skills of the learners.

On gender, the hypothesis two (2) the report of analysis on female and male chemistry learners taught with virtual environment were rejected. The findings is agreed with Martin and Parker, (2014) who uncovered that female are more than male faculty in adopting and utilising virtual environment among the faculty members. The finding agreed with Fabunmi (2012) who originated that male students had knowledge of virtual learning than female students. More so, the findings agreed with Craig (1999) who established that female students acquire more knowledge through exposure to virtual learning. However, this result disagrees with the outcome of Khairulanuar, Nazre, Sairabanu, and Norasikin (2010) who reaffirmed that gender differences which favoured male students.

On students achievement, the report of analysis on hypothesis on the performances of high, medium and low achievement taught with virtual environment were not rejected. The findings disagreed with the conclusion of Ajaja and Eravwoke (2010) who mentioned that the students attitude towards learning may brings differences in their achievement level. The findings agreed with Meisner, Hoffman and Turner (2008) who established that male students performed averagely higher than the regular students in term of their achievement tests. Similarly, the finding concurs with Olibie, Ezoem and Ekene (2014) who stressed that categories of students achievement were collapsed due to low counts in respects of some variables. The finding also in line with Olibie, Ezoem, and Ekene (2014) who established the low percentages marks of students were recorded when exposed to virtual learning. In essence, the findings is favoured Herga, Čagran and Dinevski (2016) who established the statistically significant difference of pupils mean and their achievement in primary chemistry. However, it can be deduced that gender is not a factor for virtual learning.

\section{Conclusion}

One can conclude that the study of virtual learning enhances students' understand- 
ing of laboratory chemistry concepts, acquisition and improve performances in chemistry as an alternative to actual chemistry laboratory in Nigerian Senior Secondary Schools. It is as well profitable for male and female Chemistry students of the same environment, to learn chemistry through virtual application could prop up their interest for enhanced performance of chemistry students in Nigeria.

\section{References}

Abeldina, Z, Moldumarova, Z., Abeldina, R. \& Moldumarova, Z. I. (2015). Virtual learning space in the system of elearning. Mediterranean Journal of Social Sciences. 6(5), 478-483.

Ajaja, O. P. \& Eravwoke, O. U. (2010). Effects of cooperative learning strategy on junior secondary school students achievement in integrated science. Electronic Journal of Science Education, 14(1), 23-45.

Altun, E. H., Feyzioğlu, B., \& Demirağ, B. (2011). Liseler için yapılandırmacı öğrenme etkinlikleri ile zenginleştirilmiş etkileşimli sanal kimya laboratuvarı geliştirilmesi. TUBITAK project, number of 108K293,2011.

Arokoyu, A. \& Ugonwa R. C. (2012). Assessment of Resource Availability for Chemistry Instruction in the Secondary Schools in Rivers State. Journal of Emerging Trends in Educational Research and Policy Studies (JETERAPS), 3(3), 346-351.

Mutlu, A \& Şeşen, B. A. (2016). Impact of virtual chemistry laboratory instruction on pre-service science teachers' scientific process skills. http://creativecommons.org

Bouchard, P. (2011). Network promises and their implications; In The Impact of Social Networks on Teaching and Learning [online monograph]. Revistade Universidad Sociedad del Conocimiento, 8(1),288-302.
Celestine, A. (2013). Recommendations for teaching of higher school Chemistry. American Chemical Society Publishers.

Copriady, J. (2014). Teachers competency in the teaching and learning of Chemistry practicals. Mediterranean journals of Social Sciences, 5(8)312-318.

Craig, D. V. (1999). A league of their own: Gender, technology, and instructional practices. Atlantic City, New Jersey," National Educational Computing Conference proceedings, Atlantic City, NJ., 200-220.

Dalgarno, B., Bishop, A., G. \& Bedgood J., D., R. (2003). The potential of VL. for distance education science teaching: reflections from the development and evaluation of a virtual chemistry laboratory, Universe Symposium, Sydney, Proceedings Book.

Dede, C. J., Salzman, M. \& Loftin R. B., (1994). The development of a virtual world for learning newonian mechanics. Multimedia, Hypermedia, and Virtual Reality-Models, Systems, and Application First International Conference, Moscow-Russia.

Domingues, L., Rocha, I., Dourado, F., Alves, M., \& Ferreira, E. C., (2010). Virtual laboratories in (bio) chemical engineering education. Education for chemical engineers, 5(2),22-27.

Ede, E. O. \& Ariyo, S. O. (2014). Assessment of the skills possessed by the teachers of Metalwork in the use of computer numerically controlled machine tools in technical colleges in Oyo State," Journal of Education and Practice, 5(31), 28 -33.

Fabunmi, F. A. (2012). Undergraduate students' perception of the effectiveness of ICT use in improving teaching and learning in Ekiti State University, Ado-Ekiti, Nigeria. International Journal of Library and Information Science, 4(7),121-130.

French, M., (2014). March Music Professional Learning Committee," 
Meeting minutes. Fuel Education, Inc.. 4,(2014), 237-251.

Gambari, A. I. \& Yusuf, M. O., (2014). Attitude of Nigerian secondary school students' towards cooperative learning strategies. Delsu Journal of Educational Research and Development, 12(1),100-131.

Glynn S. M., Taasoobshirazi. G, \& Brickman, P. (2007). Nonscience majors learning science: A theoretical model of motivation. Journal of Research in Science Teaching, 44(80), 1088-1107.

Glynn, S. M., Taasoobshirazi, G. \& Brickman, P., (2009). Science motivation questionnaire: Construct validation with non-science majors. Journal of Research in Science Teaching, 46(2), 127-146.

Herga, N. R., Čagran, B. \& Dinevski, D. (2016). Virtual laboratory in the role of dynamic visualisation for better understanding of chemistry in primary school," Eurasia Journal of Mathematics, Science \& Technology Education, 12(3), 593-608.

Hettiarachchi, S. \& Wickramasinghe S. (2016). Impact of virtual learning for improving quality of learning in higher education, 2nd International Conference on Education and Distance Learning. Colombo, Sri Lanka.

Hinkle, D. E., Wiersma, W., \& Jurs, S. E. (2003). Applied statistics for the behavioural sciences (5th ed.). Boston, MA: Houghton Mifflin.

Hume, A., \& Berry, A, (2013). Enhancing the practicum experience for preservice teachers ther ough collaborative $\mathrm{CORe}$ design with mentorn teachers. Research in Science Education, 43(5), 2107-213.

Jasieński, M., (2014). Features of an elearning environment which promote critical and creative thinking: choice, feedback, anonymity, and assessment. International J. Continuing Engineering Education and Life-Long Learning, 24(3/4), 237-251.
Jimoh, A. T., (2004). Influence of gender difference on students' achievement in chemistry. Nig. Journal of Educational Studies and Research, 2(10), 88- 94.

Khairulanuar, S., Nazre, A. R., Sairabanu, O. K. \& Norasikin, F. (2010). Effects of training method and gender on learning 2D/3D geometry. Journal of Computers in Mathematics and Science Teaching, 29(2), 175-188.

Lopukhova, J. \& Makeeva, E., (2017). Creating Virtual Learning Environment: Shared Online Learning in University Education, "International Journal for Cross-Disciplinary Subjects in Education (IJCDSE), 8(2), 3045-3050.

Jeschke, S., Richter, T., \& Zorn, E. (2010). Virtual labs in mathematics and natural sciences. International Conference on Technology Supported Learning \& Training: Online Education Berlin. Retrieved on 10th February 2016, from: http://www.ibi.tuberlin.

Lawrence, O. F., (2011). Investigating the effectiveness of virtual laboratories in an undergraduate biology course. The Journal of Human Resource and Adult Learning, 7(2), 110-116.

Machina, J., (2012). Prospective teachers' preparedness to facilitate Chemistry instruction at secondary school level in Nairobi teaching practice zoneKenya," Intl. J. of Edu., 2(4), 23-34.

Martin, F. \& Parker, M. A., (2014). Use of Synchronous Virtual Classrooms: Why, Who, and How? MERLOT Journal of Online Learning and Teaching, 10(2), 192-210.

Meisner, G. W., Hoffman, H. \& Turner M., (2008). Learning Physics in a virtual environment: is the there Any. Lapen. Am. Journal Physics Education, 2(2), 87-102.

Miyake, A., Kost-Smith, L. E., Finkelstein, N. D., Pollock, S. J., Cohen, G. L., \& Ito, T. A. (2010). Reducing the gender achievement gap in college science: A classroom study of values affirmation," Science, 330, 1234-1237. 
Nikolaev, D., Chugunov, D., (2012). The Education System in the Russian Federation", Education Brief, International Bank for Reconstruction and Development, Washington.

Njoku, Z. C., (2007). Comparison of students' achievementin the three categories of questions in SSCE practical chemistry examination. STAN, 42(1), 67-72.

Nwoke, B. I. \& Akukwe, A. C. (2012). Teacher's perceptions of the Benefits of ICT on students' performance in Mathematics," Journal of Educational Media and Technology, 16(1), 135139.

Olorundare, A. S. (2011). Advancement of the theory and practices in science education within the content of the Nigerian educational system," Lead Paper Presented at 1st Annual International Conference on Education at Osun State University Ipetu-Ijesa.

Olibie, E. I., Ezoem, M. N. \& Ekene, U. S., (2014). Awareness Of Virtual Learning Among Students Of Two Nigerian Universities: Curriculum Implications. International Journal of Development and Economic Sustainability,2(1), 4862.

Olson, V. E., (2002). Gender differences and the effects of cooperative learning in college level mathematics. Unpublished Ph.D thesis, Curtin University of Technology, Perth, Western Australia.

Omorogbe, E., \& Celestine, J. E., (2013). The challenge of effective science teaching in Nigerian secondaery schools. Academic Journal of Interdisciplinary Studies, 2(7), 181-188.

Onyekuru, U. B., \& Ibegbunam, O.J. (2013). Teaching neffectiveness of secondary school teachers in Emohua Local Government Area of Rivers State, Nigeria. European Scientific Journal, 9(28), 212-226.

Rajasingham, L., (2007). Perpectives on 21st century e-Learning in higher education. In L. Tomei, Integrating
Information and Communications Technologies into the classroom. USA: Idea Group. Information Science Publishing.

Rienhoff, R., Hopwood, M. J., Fischer, L., Strauss, B., Baker, J., \& Schorer, J. (2013). Transfer of motor and perceptual skills from basketball to darts," Frontiers in Psychology, 4, 593-612.

Rosandich, T.J., (2014). Information technology for sports management. The Sport Journal, 4(2), 1-4.

Rosemery, I. U., Oguoma, C. C., Elenwoke, E. C., \& Ogbuagu, E.O. (2016). Perception of difficult topics in Chemistry curriculum by senior secondary school (ii) students in Imo State. AASCIT Journal of Education, 2 (3) 18-23.

Schutt, S \& Linegar, D., (2013). We learn as we go: What five years playing with virtual worlds has taught us. International Journal of Virtual and Personal Learning Environments, 4(2), 124-136.

Tirp, J., Steingröver, C., Wattie, N., Baker, J., \& Schorer, J., (2015). Virtual realities as optimal learning environments in sport-A transfer study of virtual and real dart throwing. Psychological Test and Assessment Modeling, 57(1), 5769.

Unanma, A. O., Abugu, H. O., Dike, R. C. and Umeobika U. C., (2013). Relationship Between Teachers Educational Qualifications And Student's Achievement In Chemistry: A Case Study Of Owerri West LGA. IOSR Journal of Research \& Method in Education (IOSR-JRME), 1(1), 05-10.

WAEC (2013). Chief examiners' report. Lagos: WAEC, 2013.

Wright, V. Stanford, R. \& Beedle, J. (2007). Using a blended model to improve delivery of teacher education curriculum in global settings," In L. Tomei, Integrating Information and Communications. Technologies into the classroom. USA: Idea Group. Information Science Publishing. 
Yang, K., Y. \& Heh, J., S. (2007). The impact of internet virtual physics laboratory instruction on the achievement in physics, science process skills and computer attitudes of 10th grade students," Journal of Science Education and Technology, 16, 451-461.
Yohon, T., \& Zimmerman, D. (2006). An exploratory study of adoption of software and hardware by faculty in the liberal arts and sciences. Journal of Technical Writing and Сотmunication, 3(61), 9-27. 